\title{
Fetishism or Ideology? A Contribution to the Political Econ- omy of Television
}

\author{
Noam Yuran
}

\author{
Tel Aviv University, Tel Aviv, Israel, noamyuran@gmail.com
}

\begin{abstract}
A dominant approach to the political economy of television argues that television produces "audience commodity", which is sold to advertisers. It situates the economic effects of television within the sphere of subjects and subjectivity. This article presents a different approach, according to which television produces objects. Television advertising produces brands as economic objects possessing qualities that material goods cannot provide. For that purpose, the article explores a theoretical reconfiguration of the critical study of television: instead of basing it on ideology, which is primarily an epistemological category, it proposes to ground it on fetishism, understood as an ontological category. This change entails a shift in the topology of critique of the visual image. While the ideological paradigm regards images as inverted representations of reality, in fetishism, according to Marx, things "appear as what they are". This article argues that broadcast television is the distinctive fetishistic visual medium, in both the Marxian and the psychoanalytic senses of the term. Its fetish character qualifies it to production through visual presentation.
\end{abstract}

Keywords: Television, brands, celebrity, advertising, Marx, psychoanalysis, fetishism, ideology, labour theory of value

One of the dominant threads in critical research into television is informed by the concept of ideology, in its various guises within the Marxist tradition. This essay enquires into the possibility of changing the critical perspective. What could be gained by shifting focus to a concept that belongs to the later work of Marx, namely fetishism? An advantage of such a shift is evident from the different positions these concepts occupy in the work of Marx. The concept of ideology is traditionally associated with the idea of 'super-structure', that is, of an order that can be conceptually distinguished from that of material production. Following this logic, ideology is used to explain how the social organisation of production is justified, naturalised, reproduced, and so on. Fetishism, by contrast, occupies a crucial place in Marx's economic theory, as it refers to the mode of existence of commodities in capitalism. Its application to the political economy of television may explain how television is directly involved with capitalist production, rather than merely naturalising capitalist relations of production. It may indeed be applied to television, because in two traditions of thought, the Marxist as well as the psychoanalytic, fetishism involves appearance. Building on these two traditions, this article will apply the concept of fetishism to argue that television is a production machine of post-industrial capitalism. It produces economic objects, namely brands, whose appearance is entangled with their mode of existence.

The contribution I propose lies in insisting on the literal sense of this claim. Previous attempts to explain the direct role of television in capitalist production had to rely - sometimes against their declared aims - on a subjective supplement which accom- 
panies objects. Objects, according to these views, are produced in factories, and advertising produces something subjective associated with them: it produces demand for objects (Smythe 1977) or meanings of objects (Jhally 1990, Arvidsson 2006). This article argues, by contrast, that television produces the objects themselves: the economic object, which is the brand. This claim naturally entails a change in the conception of the object. It points to a historical type of change, involved with the emergence of post-industrial or post-Fordist capitalism. As regards the brand, the typical consumer commodity of contemporary capitalism, we can no longer maintain the commonsensical notion that a commodity is identical with the material object we possess when we buy a commodity. The brand, as an economic object, is not identical with the material object carrying a brand logo. It should be properly conceived as a conjunction of a material object with explicitly unreal images of it confronting us on television advertising; a conjunction of a material object with what that object is not. Some resonating phrases from Marx's section on fetishism qualify the commodity as a mysterious thing: it is "a thing that transcends sensuousness", having a "mystical character", "sensuous things which are at the same time supra-sensible" (1976, 163165). Ascribing reality to un-real brand advertising images may appear as a realisation of these qualifications - and, as we shall see, one case among several where Marx's concepts and metaphors are explicitly visualised in television.

The present argument requires a double path of enquiry, moving between television theory and political economy. It consists of six parts. Section 1 returns to two sight metaphors Marx uses in introducing the concepts of fetishism and ideology. It presents them as paradigms to two strategies of critique of the visual. While ideology turns our attention to illusory, inverted images of reality, fetishism introduces a more enigmatic form of critique centred on things that "appear as what they are" (Ibid., 166). This difference reflects a philosophical distinction: while ideology is essentially an epistemological theory, fetishism is an ontological category. Section 2 turns to television, and argues that it is the fetishistic visual medium par excellence, in both Marxist and psychoanalytic terms. This fetishistic nature is evident in the way television creates a conjunction of the ordinary and the extraordinary. This feature accompanies television from its earliest days and is brought to extremes with the phenomenon of celebrity, and especially in one of its contemporary versions, "the ordinary celebrity" (Turner 2010), which I argue renders the category of fetishism indispensable for the study of medium. Section 3 capitalises on the fetishistic nature of television to present it as a post-industrial production machine, where brands are produced in watching. It presents fetishism as completing a theoretical trajectory outlined by Smythe's (1977) and Jhally's (1990) conceptualisations of audience labour. These attempts aimed at understanding the objective role of media in capitalist production, but they stopped short of considering the possibility that advertising produces an object. This section argues that its fetishistic nature enables television to produce brands as distinguished from material objects carrying brand logos. Section 4 follows the homology between celebrities and brands to sketch an outline of television as a system of production. The celebrity, I argue, is one of the tools through which television reproduces its fetishistic nature, which allows it to produce brands. Section 5 returns to an earlier concept of Marx, that of alienated labour. It presents this as an ontological category, foretelling the logic of fetishism, and centres on a notion of the product of labour as an 'alien object' possessing life and powers, confronting labourers as a hostile agent. The ostensibly metaphorical language Marx uses to qualify the object is explicitly visualised in brand advertising. The section argues that this visualisation is not coincidental. Advertising confers a new form on the question that the concept of alienation addresses: how is it that workers produce what is not theirs? 
Viewed as labour, the consumption of advertising produces what cannot be had, which nonetheless constitutes the brand object. Section 6 addresses a similar question in more general terms: why is it that some metaphors of Marx seem to be explicitly visualised in advertising? While attesting to a measure of persistence between industrial and post-industrial capitalism, the visualisation of metaphors is at the same time a key to distinguish between them.

\section{Two Sight Metaphors}

To begin, let us recall that in introducing both ideology and commodity fetishism, Marx uses metaphors of vision. The difference between these metaphors demonstrates surprisingly well the costs and benefits of choosing either concept as an organising critical principle for the study of television.

Writing of ideology, Marx invoked the camera obscura: "If in all ideology men and their circumstances appear upside-down as in a camera obscura, this phenomenon arises just as much from their historical life-process as the inversion of objects on the retina does from their physical life-process" $(1988,42)$. This powerful metaphor shows the benefits and the limits of ideological critique in the many forms it has taken within the study of television. Broadly speaking, it presents ideology as an epistemological category, concerned with how reality is perceived by subjects. It is a unique epistemological category, in that it promises a way to proceed from the realm of illusions and consciousness to reality. Since ideological illusions are themselves grounded in reality - just as the camera obscura's inversion of optical images follows physical laws - we can, ideally, see reality as it is through the illusions that surround it, provided we have the correct key to re-orient the ideological image. However, this is also the limit of the concept of ideology: it requires the assumption of an illusion that can be dispelled in order to reveal the reality behind it. This assumption is most evident in interpretations of ideology as 'false consciousness'. But even materialist interpretations of ideology ground it on a distinction between two orders of reality. Althusser's theory was aimed at solving the impasses resulting from limiting ideology to the realm of consciousness; most notably the fact that it leaves open the question of how an imaginary representation of reality is instilled in the consciousness of masses of people $(1971,163)$. Part of his solution lies in a slight change in the definition of ideology, from being an imaginary representation of reality to a representation of an imaginary relation to reality ("ideology represents the imaginary relationship of individuals to their real conditions of existence";162). His reasoning is that while it is not clear why people must have an imaginary representation of the real world, they must have a relationship to their real conditions of existence, and this relationship is by necessity partly imaginary, in a way which no longer allows a binary distinction between the false and the true. The crucial point, however, is that this account of ideology retains the distinction between real and imaginary. Ideology retains its meaning by reference to a logically prior order of reality, the "real conditions of existence", which ideology helps to reproduce. Accordingly, Althusser's second thesis that "ideology has a material existence" (165) keeps loyal to Marx's camera obscura metaphor. It simply turns our attention from the illusory visions of reality invoked by the metaphor to the device that produces them, which is itself steeped in reality.

This is not meant to undermine the concept of ideology or its relevance to the study of television. Quite the contrary, the marvellous promise embedded in the concept of getting a glimpse of reality through illusions that mask or surround it has proven most fertile to the study of the medium. Informed by the various versions of the concept, critical studies have convincingly shown how television justifies, naturalises or familiarises capitalist economic reality, how it contains social tensions, incor- 
porates radical sub-cultures, and more (Gitlin 1979, Langer 1981, Fiske 1986, Adorno 1998, Mumford 1995, Couldry 2008). But, following the logic of the camera obscura metaphor, they approach reality by assuming that television images are not real, or that they belong to a secondary order of reality. What is omitted from this framework is the question whether we need to situate television images as belonging to the primary order of capitalist reality. Television, one might argue, is too intimately intermingled with everyday life and with economic reality to be confined to the sphere of illusion or the non-real.

For that purpose we can turn to the Marxist concept of commodity fetishism. Unlike ideology, fetishism is primarily an ontological category. It is worth recalling that the subject of fetishism concludes the first chapter of Capital, which circles one question: what is a commodity? Fetishism does not refer to perceptions of reality, but to the mode of existence of objects: to the way that commodities - apparently inanimate objects - mediate social relations. Following Žižek's interpretation $(2008,31)$, fetishism ascribes an ontological status to illusions. It refers to illusions that do not mask reality but constitute it.

As with ideology, Marx uses a sight metaphor to characterise fetishism, but this time he offers a more enigmatic illustration than the camera obscura; one of direct vision. An eye sees an object, nothing more: "the impression made by a thing on the optic nerve is perceived not as a subjective excitation of that nerve but as the objective form of a thing outside the eye. In the act of seeing, of course, light is really transmitted from one thing, the external object, to another thing, the eye. It is a physical relation between physical things" (Marx 1976, 165). Accordingly, the notion of distorted perception that informs ideology disappears. In fetishism, Marx suggests, things appear as what they really are. "To the producers, therefore, the social relations between their private labours appear as what they are, i.e. they do not appear as direct social relations between persons in their work, but rather as material relations between persons and social relations between things" (lbid., 166). In fetishism, social relations both appear as, and are, relations between things. How is this confluence possible? Let us stick to the simplest of examples. A price is a relation between things (commodity-thing and money-thing), but it encodes relations among people (it consists of what workers were paid, the producer's profit, etc.). Once we compile a list of all prices in an economy (including wages, which are the price of labour) we achieve a full description of the social relations of production in a society, comprising, exclusively, relations between things. In interpretations of Marx, fetishism is usually described in terms of concealment: objects mask the relations of production encoded in them. Why, then, does Marx use as an illustration the basic instance of direct vision? The point is that in relation to commodity fetishism, concealment and immediate vision are interchangeable. That objects conceal social relations means nothing other than that they appear immediately as objects. Prices can both conceal and embody social relations only insofar as they appear as properties of commodities, and not as social relations - as "the socio-natural properties" of commodities, in Marx's phrase (Ibid., 165). In other words, a capitalist commodity exists as an economic object (rather than just a junction in relations between people) insofar as it appears as an object, whose price is one of its object-properties. That is how the strange sight metaphor of Marx makes sense. Read literally, it means that we do not see that we see. Seeing objects means that the act of seeing, the physical relation between eye and object, is itself transparent. That is simply what being subject means in the act of seeing. The metaphor aims to demonstrate that, in capitalism, commodities are entangled with a certain sense of transparency. They are constituted as objects to the 
extent that the workers' relations to them, as part of the entirety of social relations invested in them, are transparent to the workers themselves.

Of course, Marx uses examples of sight as illustrations. He writes of appearances, but not in the strict visual sense of the term. This essay suggests that in the context of television we should read his metaphors literally, presenting ideology and fetishism as two different topologies of a critique of visual images. Ideological critique typically aims at going beyond images to decipher the reality they mask. Fetishistic critique would aim to unveil the coincidence of reality and appearance, and focus on the reality embodied in images. In the context of late capitalism, there is a good reason to literalise the metaphors, since visual images, appearance in its literal sense, have now become integral to the economy - primarily through the typical consumer good of post-Fordist economies, namely the brand, which is grounded on blurring the distinction between images and things. In the context of brands, advertising images can no longer be conceived simply as representations of things that exist independently of them. The brand, in other words, raises most sharply the challenge of conceiving visual images in ontological, rather than epistemological, terms.

The next two sections elaborate a two-stage answer to this challenge. The first stage addresses television theory, and presents various perspectives that highlight a fetishistic nature uniquely embedded in the medium. The second stage proceeds to political economy, and argues that this fetishistic nature enables television to produce brands through watching.

\section{Vision Machines}

As television is indeed a vision machine, it seems but logical to apply to it the concept of ideology, marked by the metaphor of camera obscura, rather than fetishism marked by the metaphor of direct vision. However, the study of television has shown that in comparison with other visual media, such as photography and film, television is distinguished by a sense of immediacy. Studies have demonstrated how an ideal of immediate vision has informed television history in a wide variety of aspects: the ontology and temporality of the television image (Feuer 1983, Doane 1990, Nichols 1994), its aesthetics (Simon 2005, Nichols 1994), social nature (Bourdon 2000, Marshall 1997), genre formations (Simon 2005, Spigel 1992), and more. In literal realisation of Marx's metaphor, where the eye cannot see the process of sight, television is a medium that aims at obliterating its mediating effects.

Thus, Doane has shown how, despite ostensible affinities, television is sharply distinguished from photography and film in its temporality. Whereas photography is associated with "pastness", with the capturing and preservation of a fleeting moment, television is marked by its "presentness" $(1990,222)$. It is marked by "a celebration of the instantaneous", which accounts for its fascination with catastrophes. Bourdon (2000) elaborates a parallel view which inscribes the present orientation of television on its unique sociability. The rise of recording technology, he argues, has not abolished the 'liveness' of television. Rather, we can see in retrospect that, from the beginning, live broadcast meant not only a transmission of events as they are taking place, but also the fact of shared viewing ('other people are viewing this live event at the same time that I am'). The various gestures through which television demonstrates this social sense of liveness (e.g. by the use of an anchor, who weaves recorded stories into a present event) underscore its essential role for the medium. Simon (2005) narrates how, from its earliest days, a drive to address everyday reality has distinguished television from the rest of the entertainment industry. The search for proper tools to represent everyday reality informed television's development and gave rise to distinct genres and unique aesthetic conventions. During the 1950s, 
shows like Candid Camera, quiz shows and early dramas were motivated by a fascination with what the scriptwriter Paddy Chayefsky termed the "marvelous world of the ordinary" (quoted in Simon 2005). Later on, in the 1960s and the 70s, documentary television adopted cinema verité conventions of avoiding commentary and interference in the filmed event, creating a sense of direct contact with filmed reality. The 1980s saw the rise of factual television with infotainment, tabloid TV, crime-time television and on-scene television. These genres, using new video technologies, created a "raw" video aesthetic: "the video image connoted an up-close-and-personal immediacy, an unvarnished reality that was lost in the chemical processes of film" (Ibid., 189). The reality genre can be seen as the culmination of the medium's search for tools to convey an immediate presentation of everyday reality. Thus Nichols (1994) claims reality TV to be a perversion of the documentary tradition, where, instead of representing an absent referent, television "absorbs" it. Reality TV "cannibalizes and assimilates the referent into a different type of substance" (52). The presentcontinuous temporality of shows like Cops, and its accompanying sensation of contingency, induces a sense of viewing as immediate presence: "We are at the moment of filming: 'Nothing has been changed, except, You are there'” (54).

Running through these diverse observations is a drive toward an ideal of unmediated vision, of seeing things 'as they are'. They present television as a medium that aims to conceal its mediating effects. The illusory nature of this ideal suggests an affinity between television and fetishism in its Freudian sense. In psychoanalysis, fetishism denotes a constitutive split of the visual field. The fetish is a unique object of sight, which allows the (male) subject to hold two contradictory positions: knowing that women lack penises, yet believing that they have them. A similar visual split characterises television's gaze upon everyday reality, as viewers are induced to various forms of contradiction between knowing and believing: knowing that images are mediated, yet viewing them as unmediated; viewing images as referring to both ordinary and extra-ordinary reality; viewing them as simultaneously mundane and marvellous and, sometimes, as both fictitious and real, at once intimately close and unreachably distant. This split gaze was apparent already in the early days of one of the genres most readily associated with television, the sitcom. It was epitomised in the many series starring real-life couples playing fictitious couples. As Spigel (1992, 157 ) writes: "in quite contradictory ways, the ideal sitcom was expected to highlight both the experience of theatricality and the naturalism of domestic life. At the same time that family comedies encouraged audiences to feel as if they were in a theater watching a play, they also asked viewers to believe in the reality of the families presented on the screen."

Fetishism has an established place in film theory (Metz 1985, Mulvey 1989), but is less prevalent in television theory. In fact, Ellis distinguishes broadcast television as being less fetishistic and voyeuristic than film. Its characteristic familiarity and intimacy, smaller-than-life-size images and necessary minimalism as regards visual details undermine the fetishistic nature of the television screen $(2001,130)$. These observations rest on an understanding of fetishism in terms of a unique visual style. Yet we should recall that in its Freudian sense, fetishism is a mode of seeing rather than a type of visual image. Moreover, in contrast to the excessive visibility that we identify as fetishistic in film, the fetish, in its origin in Freud, is actually an unnoticeable object. The fetishist has the advantage that "the meaning of the fetish is not known to other people", which allows him easy access to his erotic object (Freud $1927,154)$. It may be that fetishism's prevalence as a concept in film studies has led us to identify it with an excessive and recognisable visual style. But this visual style may actually reflect the fact that film has no recourse but to visualise the fetish. Con- 
versely, that television images appear less fetishistic in style may reflect that its mode of seeing is already fetishistic.

A consideration of the difference between television celebrities and film stars suggests that television is, indeed, constitutionally the true fetishistic medium. Marshall (1997) argues that television celebrities offer various forms of intimacy, derived from the domestic nature of the medium. In cinematic texts, film stars maintain integrity of being. The characters they play live in worlds separate from the film viewer's. On television, by contrast, the celebrity's aura of distinction is "continually broken by the myriad messages and products that surround any television text". This difference becomes evident when film stars appear on television talk shows. Here they must make a direct approach to the audience, represented by the host. They are humorously compelled to reveal things about themselves which break down the barrier between the personal realm and their public persona. Unfortunately, Marshall foists a quantitative view on these differences, arguing that "the aura of the television celebrity is reduced" in comparison with film (121-6). This conclusion obscures a crucial possibility: that the television celebrity is specifically marked by a fetishistic split. Images of film stars may seem more fetishistic (larger than life, glamorous, remote). But the ordinariness and proximity of television celebrities prove that they are situated within a fetishistic condition of seeing, as they appear both ordinary and distinguished by some elusive trait that constitutes their celebrity status.

The emergence of the "ordinary celebrity", in Turner's (2010) phrase, most notably in the reality genre - celebrities who explicitly lack exceptional talents but "perform their ordinariness with some degree of specificity or individuality" (22) - should thus be seen as thematising the condition of celebrity, and of television, as such. They bring the fetishistic condition that characterises television to its extreme, remaining celebrities despite their overt ordinariness. A related transformation in celebrity culture highlights a convergence of the Freudian and Marxian senses of fetishism with regard to television. The "hypertrophic celebrity", a term coined by Mole (2004), refers to various reality formats that reflexively reveal some of the mechanisms involved in the production of celebrity. Traditionally, celebrities could be produced only via concealing the mechanisms of their production, in order to highlight the unique qualities of celebrated individuals. In formats like American Idol, however, the mechanism becomes the show's explicit theme: "The structure of the apparatus is becoming as much an object of fascination as the individuals it promotes" (2004). This new phenomenon underlines the need to shift our critical focus on television from ideology to fetishism. The assumption that the apparatus producing celebrities must be concealed makes perfect sense within the paradigm of ideology, which assigns a role to illusory beliefs. The exposure of the apparatus calls for the use of the concept of fetishism, which makes it possible to account for illusions that prevail, whether or not people actually believe in them. That is the crux of Žižek's interpretation of the concept. In fetishism, he writes, subjects need not hold illusory beliefs, because "the things...themselves believe in their place" $(2008,31)$. With fetish objects Žižek's example is money - people do not believe in their mysterious powers but behave as if they do. The new forms characterising the institution of celebrity provide the clearest examples of this enigmatic concept of illusion as embedded in reality. They point to an illusion, implied by the very existence of celebrities, that nonetheless is not necessarily held as a subjective belief. Indeed, with the reality genre, television itself has made it practically impossible to hold the belief that celebrities are superior. Mole, for example, is baffled by a certain celebrity whose "selling point is her entertaining ignorance" (2004). What this indicates is that the institution of celebrity is not reducible to our mental attitudes toward celebrities, whose existence attests that no 
matter what people actually think, enough people behave as if celebrities are different from the rest of us - at some moments, enough people prefer the trivialities of an ordinary celebrity's life over those of the ordinary people around them.

The new forms of celebrities demonstrate a further meaning of Marxian fetishism, which Žižek describes as a substitution of a structured network with one of its elements, where "an effect of the network of relations between elements appears as an immediate property of one of the elements" $(2008,19)$. The model for this substitution is found in Marx's comment that "one man is king only because other men stand in the relation of subjects to him. They, on the other hand, imagine that they are subjects because he is king" (1976, 149). This type of misrecognition can be applied verbatim to the celebrity: 'a person is a celebrity only because other people watch her as a celebrity. They, on the contrary, imagine that they watch her thus because she is a celebrity.' In a literalisation of Marx's sight metaphor, what is concealed from our sight of the celebrity is the fact of sight itself, the way our viewing constitutes the celebrity. One is a celebrity insofar as we view her as a celebrity, while we have to assume that she is a celebrity regardless of our relation to her.

The emergence of new forms of celebrity raises a further possibility. It suggests that the change of focus from ideology to fetishism reflects a historical change in television production. It suggests that fetishism and ideology are not only theoretical concepts but can be understood as associated with two practical paradigms in the production of television. Long before the emergence of ordinary celebrities, scholars have noted that the celebrity is but an ordinary person. Boorstin, in a text from the beginning of the 60s which today is bound to appear prophetic, wrote that the celebrity "is usually nothing greater than a more publicized version of us" $(1963,83)$. Similarly, Langer (1981) put forth the theoretical riddle of why television does not produce stars but personalities. But in their time, such texts aimed at the effect of exposing a truth which is hidden to the viewers. To continue the quote from Boorstin: "we imitate them as if they were cast in the mold of greatness", but in imitating "we are simply imitating ourselves". Television production practices at that time indeed called for this theoretical gesture of exposure of a hidden truth. Celebrities typically did have some kind of factual uniqueness about them: an extraordinary achievement, a talent, beauty. What Boorstin exposed was that such a feature, while helping achieve a celebrity status, had little to do with the mode of existence of the phenomenon of celebrity. But that means that television itself followed an ideological mode of production, in the sense that it relied on illusions held as subjective beliefs - those beliefs that the 'ordinary celebrity' practically dispenses with.

This historical transition from ideological to fetishistic modes of television production may shed further light on the theoretical relation between them. It allows us to present ideology and fetishism in terms of a conceptual opposition, which nonetheless forms a continuum. Both concepts aim to explain how illusions are embedded in social reality. Ideology is essentially an epistemological theory in that it refers to illusions which at least in part reside in consciousness. Fetishism refers to illusions that no longer need be (or cannot be) subjectively held, as they are fully embedded in material practices. For that reason, fetishism offers an ontology. It refers to objects that take the place of beliefs: objects whose existence implies an illusion that is no longer consciously held. Fetishism, in a sense, designates the coming into existence of an object: the emergence of an object as alien, a social object whose effects are irreducible to subjective attitudes. This conceptual relation may be what lies at the heart of Baudrillard's claim that fetishism sketched for Marx "the lived ideology of capitalist society - the mode of sanctification, fascination and psychological subjec- 
tion by which individuals internalize the generalized system of exchange value" $(1981,88){ }^{1}$

The ordinary celebrity is not just a subject. It is entangled with a certain object: the television screen and our practices involved with it. Our practices regarding the celebrity (e.g. turning a special attention to the trivialities of the life of an ordinary person, who is mysteriously different from the ordinary people who are our friends and family members) are at the same time practices involving television. So we need to return to the question of the relation of television to the institution of celebrity, but this time from a different angle. Some writers attribute the shifts in celebrity culture not just to reality television but also to the proliferation of social networks (Mole 2004, Turner 2010, Gamson 2011). This conclusion seems warranted by the decentralised structure of the Internet. Yet it may be premature: social networks indeed mediate 'ordinary' reality, but it is yet to be proved whether they can achieve the fetishistic confluence of ordinary and extraordinary. The proliferation of channels compiling ongoing feeds of the amazing, the bizarre and the unique suggests that the Internet can more easily present either the ordinary or the extraordinary, but is less suited to fuse them. But, not to ground this conclusion solely on partial observations, we should return again to Boorstin's prophetic text. The most remembered part of his book is his definition of celebrities as "known for [their] well-knownness" (1963, 67). It's a misfortune that this phrase is usually quoted today as no more than a derogatory comment on the shallowness of celebrity culture. What is overlooked is the conceptual definition this phrase enfolds, which has become ever more relevant with the co-existence of television and the Internet. Read in retrospect, this definition both expresses the fetishistic nature of the phenomenon of celebrity, and ties it to television. On the one hand, 'known for their well-knownness' is a formula of fetishism, because it refers to an indistinguishable difference that nonetheless distinguishes the celebrity from ordinary persons. It grounds the existence of the celebrity on a mysterious quality, irreducible to any of the actual traits of her person. It describes the simultaneity of the ordinary and the extraordinary in the celebrity. Without referring to the concept, Boorstin also spells out a certain sense of Marxian fetishism involved with the celebrity, by acknowledging the fact that the celebrity is created by the people who relate to her as celebrity: the celebrity "is made by all of us who willingly read about him, who like to see him on television, who buy recordings of his voice and talk about him to our friends" (Ibid.). On the other hand, as evident only in retrospect, Boorstin's formula allows us to conceptually tie this fetishistic nature to the technological infrastructure of broadcast television, in its difference from decentralised media. Read literally, "known for their well-knownness" refers to the fact that our relation to a celebrity implies others. It means that we know her as someone who is well-known, that is, as a stand-in for an indistinguishable, anonymous group of others. In other words, it can be referred to the shared nature of television. On television, everyone is indeed potentially known for their well-knownness, due to the fact that we watch as part of a crowd, together with unrecognisable others. The mysterious difference that distinguishes a celebrity is a reflection of the fact that she is a stand-in for a crowd whose only trace of existence is the celebrity herself. Read thus, the celebrity can be understood as a personalisation of the sociality of television, giving expression to its

\footnotetext{
1 Žižek's (2008) Lacanian interpretation of commodity fetishism provides a model for its understanding as a historical category, which can be described as a form of persistence through repression: feudal relations of domination are abolished and transformed into relations of exploitation mediated through commodities, where they no longer appear in the form of social relations. In other words, the fetish emerges historically as an object that encodes social relations which are no longer reducible to interpersonal relations.
} 
shared nature, which is irreducible to the technological features of the screen, yet distinguishes it from other, allegedly, very similar ones. So in a way, the emergence of the ordinary celebrity may indeed be linked to the Internet, though negatively. The celebrity can practically serve as a marker of the uniqueness of the television screen, and the intensification of celebrity culture can be understood as answering the economic necessity of television to distinguish itself from the Internet.

The ordinary celebrity highlights a fetishistic mode of seeing, embedded in the medium of television. It therefore opens the way for presenting the direct economic role of television in terms of the production of brands. A simple parallel informs my argument here. Celebrities are ordinary people distinguished by an aura maintained by the medium of television: similarly, brands can be regarded as ordinary objects distinguished by an aura opposed to their ordinariness. Furthermore, as the ordinary celebrity makes it necessary to understand the illusory aura as being constitutively real, it can be argued that the illusory images of television advertising constitute the reality of the brand object.

\section{The Fetishistic Gaze and the Production of Brands}

A foundational thesis in the study of the political economy of media was proposed in the 70s by Smythe (1977). It set a framework for a study of the direct involvement of media in capitalist economy by conceptualising the consumption of media in terms of labour. According to this framework, commercial media produce a unique type of commodity, the audience commodity - the attention of television viewers - and sell it to advertisers. It is important to return to Smythe, because his thesis pointed in a direction that guided much research, but its potential was not fully realised. Smythe identified the need to forego the ideological study of media, suffused by the use of "subjective mental entities" such as "messages," "information," "meaning," "education," "orientation," "manipulation", etc. These should be replaced by a framework that seeks "an objective reality" of media which would answer the question "what economic function for capital do they serve?" (Ibid., 1-2). Mass media are unique in that they belong simultaneously to the superstructure and to infrastructural production (3). However, this change of focus from subjective mental entities to objective reality was not fully realised, because it stopped short of the object. Smythe aims at incorporating the labour of the audience within the framework of capitalist production (15-16). Yet he does not enquire whether this aim requires a conceptualisation of the objects produced as commodities. He does not enquire whether the incorporation of advertising within the process of production entails a new type of economic objects, markedly different from the typical goods of industrial capitalism. From his perspective, eventually, the commodities are the same objects of industrial capitalism - nutrition, clothing, and so on - and advertising-as-labour produces the demand for them. That is why Smythe's explanation of the labour of the audience eventually recalls the "subjective mental entities" which he strived to banish from the critical study of media. "The work which audience members perform for the advertiser to whom they have been sold," he writes, "is to learn to buy particular 'brands' of consumer goods, and to spend their income accordingly. In short, they work to create the demand for advertised goods which is the purpose of the monopoly capitalist advertisers" (6). "Learn[ing] to buy" may be read as a materialist rendering of a subjective mental entity, but it entails a subjective mental entity nonetheless, not radically different from the concepts of manipulation, education, and information which Smythe tried to dispel.

This regression into the language of ideology is not necessarily a theoretical flaw in Smythe's argument. It may reflect a specific historical practice of advertising which 
was itself ideological, and paralleled the ideological mode of production of celebrities. In Fordist capitalism, before the emergence of branding, advertising typically followed realist conventions (Arvidsson 2006, 48). It indeed sought to educate, to "make consumers behave and desire in a certain way" (Ibid., 41). Quoting an early advertising professional, it worked under the assumption that people could be made to "accept, desire and demand the things that are part of the increased standard of living" (45). These realist conventions explain Schudson's (1984) early definition of advertising as "capitalist realism" - the capitalist equivalent to the official, state-sanctioned art in the Soviet Union. Schudson grounds the parallel on stylistic similarities, such as the use of generic characters, representative of social groups in both advertising and the art of socialist realism, and the reliance of both on general and easily recognisable scenes. But this stylistic similarity unearths an ideological layer that was imbued in Fordist advertising. As socialist realism aims at presenting non-alienated labour as a consummation of humanity, advertising "glorifies the pleasures and freedoms of consumer choice in defense of the virtues of private life and material ambitions" (2013 [1984], 218). Fordist advertising was ideological in the sense that, while promoting a specific commodity, it promoted also the general idea of consumption as a realisation of happiness. To quote Schudson, it was "capitalism's way of saying 'I love you' to itself" (2013 [1984], 232). ${ }^{2}$

Branding involves a shift away from realist conventions (Arvidsson 2006, 62). Against this background, the concept of fetishism is called for in order to complete the trajectory outlined by Smythe. As an ontological category that involves existence with appearance, fetishism suggests a simple though somewhat counterintuitive answer to the question of what is produced by audience labour. It is not a subjective relation to an object, a commodity, but the object itself. Recalling Marx's metaphor that immediate sight constitutes the object, I suggest that in seeing brands in commercials we take part in their production as economic objects. In their fantastic appearance in advertising, we see them 'as they really are': a conjoining of ordinary objects with images that refer to what is foreign to these objects. This claim can make sense if we accept that with the emergence of brands the commodity has radically changed; that is, if we assume that the economic object called 'brand' can no longer be unequivocally identified with the objects we buy, possess and use - shoes, watches or soft drinks which carry brand logos. Klein $(2009,21)$ has indicated such a change. The brand, she writes, comprises a component "that can only be described as spiritual", and she refers to branding as "corporate transcendence". The concept of fetishism makes it possible to take these notions at face value. The brand is spiritual and transcendent in the sense that it comprises a material object and what the material object is not. A model for such an explanation may be found in some of Guy Debord's condensed formulations in his application of Marxist categories to the economy of the spectacle: "The spectacle that falsifies reality is nevertheless a real product of that reality. Conversely, real life is materially invaded by the contemplation of the spectacle" (undated, 8).

An important step toward the understanding of advertising in terms of production of objects is made by Jhally (1990). For that purpose he indeed turns to fetishism, in the Marxist and psychoanalytic meanings, as well as its uses in anthropology. Two related points suggest, however, that this was still a partial step. Firstly, Jhally's an-

\footnotetext{
${ }^{2}$ After the collapse of the Soviet bloc, Buck-Morss (2002) studied in detail the surprising similarity revealed in retrospect between Fordist capitalism and the Soviet world. Both systems fostered visions of mass utopia, which, despite the fierce ideological battle of the Cold War, shared similar imageries and language, similar 'dreamworlds'.
} 
swer to the question of what is produced by the labour of audience is "meaning". Advertising charges commodities with meaning of which they were divested in capitalist anonymous mass production $(1990,45-53)$. In a sense, this idea forces the epistemological terminology of ideology on a perspective informed by the ontological category of fetishism. Secondly, Jhally's account relies mainly on interpretation of content. He shows that a significant share of advertisements visually stage various prototypes of fetishistic scenes: products that possess human qualities; products that invoke emotional reaction, irrespective of their uses; products that transform people; products that change social relations; products that mediate social relations; and products that capture natural forces (Ibid., 162-3). These are indeed clear visualisations of fetish objects in the various traditions Jhally uses. What raises the doubt that his application of the concept is partial is precisely the fact of visualisation, the fact that he studies such clear staging of fetishism. This means that he applies fetishism to the contents of visual images rather than to a mode of seeing. In both the Marxist and the Freudian traditions, a fetish object does not - and perhaps cannot - appear 'fetishistic'. To recollect, in Freud the fetish is an ordinary object that escapes the attention of everyone but the fetishist, and in Marx fetishism is grounded on the most mundane feature of commodities, namely, the fact that they have a price (that is, a price which confers objective form to social relations). A long tradition of the study of fetishism in film and visual culture may have led us to forget that when Marx coins the term, he has in mind the prosaic commodities that recur throughout the first chapter of Capital: tables, linen, coats, iron, coffee, tea, corn. More specifically, Jhally's focus on visual content, rather than mode of seeing, renders his argument indifferent to the question of medium. It applies equally well to any type of visual medium. It thus seems to fall into the trap that Baudrillard describes as a "fetishization" of fetish theory: when the concept of the fetish is applied within the framework of false consciousness, it involves a "fetishization of the conscious subject or of a human essence" (1981, 89); "Instead of functioning as a metalanguage for the magical thinking of others, it turns against those who use it, and surreptitiously exposes their own magical thinking" (90). To relate this account to Jhally: enquiring into the visual content of images, regardless of their medium and the mode of seeing, implies the idea that the mere confrontation with images exerts an uncanny influence over people.

To take the required additional step from interpreting advertising images to addressing them as immersed in the medium of television and its specific mode of seeing, let us turn to a well-known series of Coca-Cola commercials, entitled "Happiness Factory". These commercials explicitly visualise some of the central themes that occupy us: labour, production, mystery and money; and can thus be seen as thematising the brand as such. Considering them against Jhally's argument points to a further advantage they hold: in terms of their content they do not stage fetishism, and in one sense even deny it. They indeed present fantastic wonders associated with Coca Cola, but the telling point is that they present them as hermetically isolated from real life, having no effect on people whatsoever. This could be taken as an evidence that they rely on, and effectuate, a seeing mode which is already fetishistic. These advertisements present fantastic events taking place inside a vending machine. One of the commercials begins with a street view: a young man inserts a coin into the machine. As the coin slides in, the view moves to the entrails of the vending machine. The coin generates a fantastic process of creating a Coke bottle in a magical world, lacking visible borders and occupied by cute creatures and weird contraptions. Bulbous insects carry the bottle as they fly; furry creatures give it a nice clean; a tube descends from the blue sky to fill it with Coke; round, penguin-like creatures walk around in a frozen world, building snowmen to cool the drink down; and finally, a merry proces- 
sion, accompanied by fireworks, carries the bottle toward the exit. At this point we return to the street view to see the young man pick up his bottle and walk away from the machine as he takes a drink, in what is a completely trivial portrayal of drinking a soda. At the last moment, he stops and looks at the bottle, then turns toward the machine, nods his head, and walks away - as if wondering for a moment about the story, obviously hidden, of that bottle.

The key to this advertisement is the split or barrier between the fantastic reality inside the machine and the trivial realism of what takes place on the street. It structures the advertisement around a sort of double negation, which makes it possible to reconcile the fantastic and the ordinary. It associates Coke with unreal images, and at the same time encloses these images within the machine and beyond perception. Coca-Cola is presented as a marvellous object, unrelated to material Coke bottles, and at the same time as unknowable and unreachable in consciousness. Rather than persuading, it is aimed at accommodating the fantastic images with everyday experience. The fetishistic seeing mode in which the images are immersed is implied by the split that structures them, which assures the viewers that they do not have to believe. They know very well that the real experience of Coca Cola resembles the mundane street scene rather than the marvellous series of scenes inside the machine. But taking account of the fetishistic medium in which those scenes are immersed makes it possible to attribute to them a mode of reality.

To enquire further what mode of reality this is, we need to bring in the economic perspective. In standard economic terms, brands are defined by their difference from products. The term 'brand equity' refers to the price difference between a branded product and a similar non-branded one. It is supposed to be explained by qualities other than those of the physical product. Professional marketing discourse invokes a host of subjective entities to explain this difference, which constitutes brands. They speak of brand loyalty, associations, emotional connections, and so on. While such terms may have a measure of truth, they refer to beliefs of consumers in different ways. By contrast, explicitly disavowing belief, the exampled advertisement suggests a minimal form of this difference. As a brand, Coke is constituted by what in principle is unrelated to material Coke bottles, what the physical object is not, which is presented, as unreal, right in front of our eyes. ${ }^{3}$ Of course, following this logic leads to the scandalous possibility that, with the brand, consumers pay more for something that goods cannot provide. The fetishistic gaze, in its various meanings, maintains this possibility. Following Žižek's interpretation, where fetishism refers to a situation in which people do not mentally hold false beliefs but practically behave as if they do, there is a simple sense to the reality of the fantastic images of the "Happiness Factory" commercial. It is found in the fact of paying. People know very well that Coke would deliver nothing more than the mundane experience that frames the commercial. The commercial itself assures them that they are not induced to believe the fantastic occurrences presented in it. But in buying Coke, paying the additional price of brand equity, they practically behave as if they do. In this sense, money confers reality on the explicit illusions of the commercial.

Interestingly enough, money occupies a key role in the commercial. The entrance to the land of wonders inside the vending machine follows the movement of the coin

\footnotetext{
${ }^{3}$ In other words, professional marketing discourse is motivated by the insistence that consumers must get something in return for the extra cost of brands, even if this something is illusory, false or manipulated. It circumscribes the possibility marked by fetishism that consumers pay for what they cannot, in principle, attain. In this possibility that extra cost is produced by audience-labour. And conversely it is the cost itself, as it is paid in practice, that confers reality on the unattainable, produced among other things through advertising.
} 
inserted into it. Once inside the machine, it is transformed into a golden coin, huge and heavy in comparison to the creatures inhabiting this land of wonders. Rolling down the fantastic landscape, it ignites the whole chain of events. It is not paid to the fantastic labourers on the assembly line inside the vending machine, but rather triggers it, in causal manner, through its physical materiality. In the fantasy, it is not exchanged for Coke, but in a sense transformed into it, taking a direct part in its production. This last element completes the picture, and brings us back to our starting point. Recalling the strange notion that in fetishism things 'appear as what they are' we should note that the commercial actually offers a complete critical theoretical statement. Its only deceit is its claim that it is deceiving. My main argument about fetishism, television, labour and brands can be summarised by taking the commercial at face value. The only revision needed is to refer its images to the medium of television itself: television is a mysterious assembly line (and a very joyful one); it partakes in the production of brands, which comprise physical objects together with images of what these objects cannot be; the unreal element is made real through money. To put it in the framework of Marxist economic theory, the coin in the commercial is a direct embodiment of surplus value: it represents the added value that constitutes the brand in comparison with the material product. It is literally produced in watching: the value added is ascribed to the fantastic images that run in contrast to the material existence of Coke bottles. And it transforms to profits in reality, as consumers pay added price for what they cannot receive. ${ }^{4}$

To pursue this possibility we should return to the analogy between celebrities and brands. Both phenomena entangle the ordinary and the extraordinary. I would argue that more than an analogy is at stake here. Both phenomena can be seen as elements of television as a system of production.

\section{Television as a System of Production}

In the context of celebrities, as made evident with the ordinary celebrity, the need for the concept of fetishism is inescapable. This context raises most forcefully the need to account for an illusion that has an ontological status, an illusion that does not obscure reality but constructs it. This essay suggests applying the same view to brands, where this need may be less apparent. However, there may be more than a homology between brands and celebrities. They can be seen as complementary elements of the same social production system enfolded in television. In sum: by producing celebrities, television reproduces its own fetishistic condition, and thus maintains the context where brands can be produced. Celebrities, who articulate the social infrastructure of broadcast television as a shared medium, also embody the difference between televised reality and unmediated reality, which makes possible the presen-

${ }^{4}$ It is important to distinguish this conception of the brand from Baudrillard's simulation. Simulation also assigns reality to images, but it is aimed at the idea of "substituting the signs of the real for the real" $(1994,2)$. I use the concept of fetishism to ascribe reality to images, not as substitutes of the real, but quite the contrary: they are real, in an economic context, insofar as they coexist with real objects; maintaining a radical difference from them while together comprising the commodity. That is why they can be conceived within the notion of surplus in the various meanings of the term. Being foreign to objects, they can be added to them. They are the product of the labour of watching, which accounts for surplus value. And finally, in Lacanian terms, they can be seen to embody surplus enjoyment, which Žižek (1999) defines (apropos of Coca Cola) as "the pure surplus of enjoyment over standard satisfactions". Surplus enjoyment, within this framework, designates the object of desire, but in a very special way: it is what we seek in our objects of desire, which we can never get from them. 
tation and production of brands. In Marxist terminology, celebrities can thus be conceptualised as part of the constant capital of television, equivalent to the status of machinery in industrial capitalism.

The ritual approach to media is most helpful in elaborating this possibility. Like fetishism, the ritual approach to media shows how things of the order of belief are objectively maintained in media. Rituals, as Couldry argues, "reproduce categories and patterns of thought in a way that bypasses explicit belief" $(2003,24)$. A relevant example of a media ritual is a meeting between celebrities and ordinary people. In such moments, the boundary between celebrities and ordinary people is crossed, but for the ritual approach the crucial effect of this crossing is that the boundary itself is naturalised and reaffirmed. Encounters between celebrities and ordinary people reproduce and naturalise the assumption that celebrities are distinguished from ordinary people. However, such moments reproduce not only the category of celebrity but, as a further effect, the distinction between unmediated and mediated reality. As Couldry writes: "The wider resonance, or framing, of such acts derives from the way that the media person/ordinary person distinction replicates a broader hierarchy between people/things/places 'in' the media over people/things/places not 'in' the media" (2003, 26-7). Couldry writes about media in general, but his argument, it is important to note, is germane to television. In contrast to networks and to film, television can sustain a binary distinction between 'in' and 'not in'. In film the distinction is much weaker, as it rests primarily on the distinction between the real and the imaginary. Moreover, film lacks the live aspect, which supports the distinction between inside and outside (that is why people can 'be on television' but cannot 'be on film'). Networks, in their rhizomatic, open-ended interface with unmediated reality, seem not to constitute any binary distinction at all. To add the economic aspect to Couldry's claim: by reproducing the category of celebrity, television reproduces its own basic material premise: what's 'in' television, though basically similar to what's not, is nonetheless superior to it. And that is the condition that allows television to present the brand object as being similar, yet superior, to the material objects carrying that brand name.

\section{Television as Alienated Labour}

Jhally takes further Smythe's idea of audience labour, insisting that advertising literally partakes in the production of goods: "watchers labor for capital to the same extent as do wage laborers in a factory" $(1990,174)$. Another crucial contribution he makes is by bringing into the discussion Marx's concept of alienated labour. However, Jhally refers mainly to the social and psychological contents of the concept, such as the degrading and tormenting nature of labour in capitalism. Jhally cites studies where subjects describe television viewing as a harmful addiction $(1990,178-$ 9), resonating some suggestive claims of Marx - that labour "mortifies [the labourer's] body and ruins his mind"; "in his work [the labourer] feels outside himself" $(1988,74)$. These are indeed some of the claims most commonly associated with Marx's concept of alienation, but they are also the type of claims which led Wood (2004, 3-4) to argue that alienation is not an explanatory concept, but a descriptive one, which groups rather loosely various ills of capitalism. Focusing solely on them obscures the fact that when Marx provides a definition of alienation, he refers to something else. The psychological and social senses of alienation can be indeed read as referring to the historical conditions of labour in 19th century industrial capitalism. The definition of the concept, by contrast, refers in abstract terms to objects, to a peculiar notion of an "alien object" and the way it is sustained by a certain subject-object relation. For that reason it can be read as an ontological category that foretells the logic of fetish- 
ism. The various consequences of alienation, Marx writes, "are contained in the definition that the worker is related to the product of his labor as to an alien object" $(1988,71)$. To qualify this definition Marx uses what appears to be metaphorical language, which nonetheless seems to be visualised in brand advertising. The product of labour appears primarily as an uncanny object: it confronts subjects; it possesses agency, mysterious powers, a life of its own; and it expresses hostility toward the worker. Grasping what led Marx to invoke such an uncanny object can explain why it seems to be directly visualised in the way objects confront us in advertising.

Let us recall how Marx first uses the term "alienation". After noting the evident historical fact (evident, that is, in nineteenth-century industrialised Europe) that the workers become poorer the more they produce, Marx (Ibid.) writes: "This fact expresses merely that the object which labor produces - labor's product - confronts it as something alien, as a power independent of the producer". Notice that it is the object that confronts the labourer, not vice versa. This inversion, where the object assumes the active role in the relation, runs throughout the text: "the worker becomes a slave of his object"; alienation means that the object "becomes a power on its own confronting [the labourer]"; "the life which he has conferred on the object confronts him as something hostile and alien" (72); alienation entails considering "the relation of the worker to the product of labor as an alien object exercising power over him" (75).

The ostensibly metaphorical language has theoretical significance. Such language is required because what Marx aims to expose is a double sense of production, made up of two different senses, which in capitalism necessarily appear indistinguishable. Workers produce inanimate material objects, and there is not much worth noting about it. As material objects they do not possess powers, and they are certainly not hostile to the labourer. They appear animated because workers produce goods as economic objects, governed not by natural law but by a certain regime of private property. They produce material objects which are the property of other subjects. What this means is that in the practice of production the material properties of objects and their social properties are indistinguishable, considered as belonging to the same level. The exact terminology to define this situation had to await Capital. The term that is missing here is the notion of "the socio-natural properties" of commodities $(1976,165)$. (To clarify, if we answer Marx's initial enigma with the simple reply: "workers produce everything yet remain impoverished because the means of production are not theirs", we have reiterated the confusion between material and social properties of things; we pose the question in terms of material production and answer it in terms of the social properties inscribed on objects).

It is because these two senses of production are intertwined that objects assume an active role as animated hostile forces. The levelling of the material and social properties of things is the way the impoverishment of labourers is inscribed on the material infrastructure which they produce themselves - as if their impoverishment emanates directly from the objects they produced. They produce machines, with which they will then produce additional things which will not be theirs. Strictly speaking, then, Marx's uncanny object is not exactly metaphorical. It follows a metaphorical-like feature of economic reality, where social properties appear as if they are material. That is Marx's way to ascribe agency to objects. In their practice, workers relate to objects as if they are not theirs, as if belonging to another person is one of their properties. That is also why Marx refers to the way objects confront subjects and not vice versa. The two separate meanings of production can be fused insofar as the labourer's practical relation to the object appears inverted, as emanating from the 
object itself: as if 'not his own' is a property of the object and not a relation of the subject to it.

As a definition of capitalist production, alienation both problematises and describes the situation where workers produce what is not theirs. In this formulation we can now see how television brand advertising rearticulates the same basic situation. Objects confront viewers as possessing powers and life that the viewers cannot possess. In terms of labour, viewers thus continue to produce what cannot be theirs: a surplus they produce, and may even pay for, but which they cannot acquire when they buy a branded object. They produce the brand as not theirs.

\section{The Visualisation of Metaphors}

Some concepts and metaphors of Marx seem to be realised or visualised in television and brand advertising (the fetish metaphor of immediate sight, where things 'appear as they are'; the commodity as mysterious, transcendent, at once sensuous and transcending senses; the animated object of alienation confronting the labourer as possessing powers and wills). We have presented these metaphors as attesting that Marx's basic concepts, developed in the context of industrial capitalism, still apply in the new environment of late capitalism (and conversely, that what appeared metaphorical in Marx may actually be a theoretical concept). However, the visualisation of metaphors may also help us understand the uniqueness of post-industrial capitalism.

In Marx, the notion of the uncanny, alien object appears metaphorical because it is only implied. It is an abstraction that is not actualised in any specific object, because in industrial capitalism no single labourer actually produces an object. Workers produce objects in immensely complex processes involving other labourers and other objects (machines, parts, raw materials), and the alien object is suggested as the unifying principle of the system as a whole. Strictly speaking, workers typically do not produce objects, but complete small, repetitive tasks in processes of production of objects. These are the characteristics of labour that pertain to the more descriptive parts of Marx's chapter on alienated labour. Thus, an aspect of alienation is embedded in machine work: when labour is replaced by machines, it throws some of the workers "back to a barbarous type of labor, and the other workers it turns into machines. It produces intelligence - but for the worker idiocy, cretinism" $(1988,73)$. Yet this is not just a historical description of labour in industrial capitalism. It is related to the theoretical concept of alienation, because the concrete historical conditions of labour sustain the abstract definition of alienation as the production of an alien object. One should carefully read the relation between the more descriptive parts of Marx's text and the abstract definition of alienation. After exploring at length that abstract definition, Marx poses the question: "How would the worker come to face the product of his activity as a stranger, were it not that in the very act of production he was estranging himself from himself?" (Ibid., 73-4). The "act of production" - the actual reality of industrial production - appears as the condition of possibility of the abstract principle that labourers produce what is not theirs. Labour in capitalism can be considered alienated as a whole, to the extent that its organisation sustains the abstract principle of production of an alien object.

The explicit visualisation of the alien object in brand advertising may indicate that a certain inversion has occurred between the abstract principle and its historical manifestation. The alien object is now materialised in front of our eyes, but the social conditions of production which sustain it have become invisible. The object as an alien being, possessing powers and life, has become visible because, in contrast to industrial capitalism, brand objects are produced whole. They are created, indeed, by mass viewing, but not through a division of labour. Thus Marx's pathos-laden diagno- 
ses of factory work can be read, with some stretch of the imagination, as referring directly to the fantastic assembly line in the "Happiness Factory" Coca-Cola advertisement: "It is true that labor produces for the rich wonderful things - but for the worker it produces privation" $(1988,73)$; "the more powerful the alien objective world becomes which [the labourer] creates over-against himself, the poorer he himself his inner world - becomes" (72). Watching produces wonderful things, but this directly means that it produces privation: it produces the material objects we buy and possess as lacking.

By contrast, the social conditions that sustain the creation of the alien object have become invisible as they are enfolded into television. We should recall, for that purpose, that what qualifies television as a fetishistic medium is in part its shared structure. It is enfolded, as we have seen, into the personae of celebrities, if we follow Boorstin's definition of their being "known for their well-knownness". Accordingly, some of the social and psychological aspects of alienation that we find in Marx can indeed be articulated now in relation to the confrontation with the celebrity. Thus, Marx's claim that for the object to be alienated the labourer must be "estranging himself from himself" $(1988,73-4)$ resonates in the way Boorstin implicates the existence of celebrities with a way of being for the viewers who make them celebrities: "In imitating him...we are simply imitating ourselves...By imitating a tautology, we ourselves become a tautology standing for what we stand for, reaching to become more emphatically what we already are" $(1963,83)$. The celebrity implies viewers alienated from themselves, not fully being themselves, and this form of alienation is accentuated by the ordinary celebrity. In lacking talents that rationalise her difference from us, she underscores that we are somehow deficient in our very ordinariness.

\section{Conclusion: The Labour Theory of Television}

To conclude, let us put the argument in the context of Marx's labour theory of value. The controversy around this theory was revived together with the revival of interest in the idea of audience labour, mainly in the context of social media. Fuchs (2012) promotes the idea that the activities of users on social networks should be conceptualised as unpaid labour, which creates surplus value accumulated by the networks. Arvidsson and Colleoni (2012) argue against this view that the profits of social networks such as Facebook are disproportional to the activities of users. Framing the controversy in these terms reflects a theoretical choice regarding the meaning of the concept of value. It is based on the understanding of value as a measurable empirical magnitude which forms the basis for a price theory. However, the concept of value can be understood also as an analytical category. As such, there is no sense to the question of whether it is valid or not. The question regarding analytical categories is what knowledge they bring about. In Capital the concept makes it possible to pose a fundamental question: who lives off the work of whom. To answer this question there is no need to attribute substance to value. It is enough that we can ideally describe the economy as a whole in terms of value: what labour enters into the production of each and every commodity, including the special commodity of labour power. That is the general way this essay applies the concepts of labour and value to television in post-industrial capitalism; it uses them as a way to pose a question. But it shifts the emphasis of Marx's original question from the mechanism of exploitation as it is mediated through commodities to the question of their ontological status. What is the brand object insofar as we accept the assumption that it is a profit mechanism? What could be understood as labour invested in its production? What type of object is it, in light of the labour invested in it? 
The argument is based on resilience, showing how Marx's terminology, formulated at the height of industrial capitalism, remains relevant in new ways in the context of post-Fordist economy. Audiences watch commercials in exchange for television content, and their attention to advertising can be understood as labour in the most general sense that it contributes to brand equity. Not contending with this obvious sense, this article enquires what is produced through watching. Advertising can be understood as labour in a 'thicker' way because it conforms to an early Marxist abstract definition of labour in capitalism as the production of what the workers cannot own. This definition receives a new meaning in the context of post-Fordist capitalism, where brands are defined by comprising what material goods cannot be, and are nonetheless presented in advertising that partakes in their production as brands. What this means is that we have to consider the explicitly unreal images of advertising as real elements of the brand object. In other words, it means that what we see in brand advertising are not illusions concerning brands, but brand objects 'as they really are'. What sustains this possibility is a fetishistic viewing mode embedded in television, in the Marxist and psychoanalytic senses of the term.

\section{References}

Adorno, Theodor W. 1998. Critical Models: Interventions and Catchwords. Translated by Henry W. Pickford. New York: Columbia University Press.

Althusser, Louis. 1971. Lenin and Philosophy and Other Essays. New York: Monthly Review Press.

Arvidsson, Adam. 2006. Brands: Meaning and Value in Media Culture. London: Routledge.

Arvidsson, Adam, and Elanor Colleoni. 2012. Value in Informational Capitalism and on the Internet. The Information Society 28 (3): 135-150.

Baudrillard, Jean. 1981. For a Critique of the Political Economy of the Sign. Candor, NY: Telos Press Publishing.

Baudrillard, Jean.1994. Simulacra and Simulation. Ann Arbor: University of Michigan Press.

Boorstin, Daniel. 1963. The Image, or, What Happened to the American Dream. Harmondsworth: Penguin.

Bourdon, Jerome. 2000. Live Television Is Still Alive: On Television as an Unfulfilled Promise. Media Culture and Society 22 (5): 531-556.

Buck-Morss, Susan. 2002. Dreamworld and Catastrophe: The Passing of Mass Utopia in East and West. Cambridge, MA: MIT press.

Couldry, Nick. 2003. Media Rituals: A Critical Approach. New York: Routledge.

Couldry, Nick. 2008. Reality TV, or the Secret Theater of Neoliberalism. The Review of Education, Pedagogy, and Cultural Studies 30 (1): 3-13.

Debord, Guy. 1992. Society of the Spectacle. London: Rebel Press.

Doane, Mary Ann. 1990. Information, Crisis, Catastrophe. In The Logics of Television: Essays in Cultural Criticism, edited by Patricia Mellencamp. Bloomington: Indiana University Press.

Ellis, John. 2001. Visible Fictions: Cinema, Television, Video. London: Routledge.

Feuer, Jane. 1983. The Concept of Live Television: Ontology as Ideology. In Regarding Television, edited by E. Ann Kaplan. Frederick MD: University Publications of America.

Fiske, John. 1986. Television: Polysemy and Popularity. Critical Studies in Media Communication 3 (4): 391-408.

Freud, Sigmund. 1927. Fetishism. In The Complete Psychological Works of Sigmund Freud (Vol. XXI). London: Hogarth and the Institute of Psychoanalysis.

Fuchs, Christian. 2012. Dallas Smythe Today: The Audience Commodity, the Digital Labour Debate, Marxist Political Economy and Critical Theory. Prolegomena to a Digital Labour Theory of Value. tripleC - Communication, Capitalism \& Critique 10 (2): 692-740. 
Gamson, Joshua. 2011. The Unwatched Life Is not Worth Living: The Elevation of the Ordinary in Celebrity Culture. PMLA 126(4): 1061-1069.

Gitlin, Todd. 1979. Prime Time Ideology: The Hegemonic Process in Television Entertainment. Social Problems 26 (3): 251-266.

Jay, Martin. 1993. Downcast Eyes: The Denigration of Vision in Twentieth-Century French Thought. Oakland: University of California Press.

Jhally, Sut. 1990. The Codes of Advertising: Fetishism and the Political Economy of Meaning in the Consumer Society. New York: Routledge.

Klein, Naomi. 2009. No Logo: Taking Aim at Brand Bullies. New York: Picador.

Langer, John. 1981. Television's 'Personality System'. Media, Culture \& Society 3 (4): 351365.

Marshall, P. David. 1997. Celebrity and Power: Fame in Contemporary Culture. Minneapolis: University of Minnesota Press.

Marx, Karl. 1976 [1867]. Capital, Volume I. London: Penguin.

Marx, Karl. 1988 [1932]. The Economic and Philosophical Manuscripts of 1844. Amherst: Prometheus Books.

Marx, Karl. 1998 [1932]. The German Ideology. Amherst: Prometheus Books.

Metz, Christian. 1985. Photography and Fetish. October 34: 81-90.

Miklitsch, Robert. 1988. From Hegel to Madonna: Towards a General Economy of Commodity Fetishism. Albany: SUNY Press.

Mole, Tom. 2004. Hypertrophic Celebrity. M/C: A Journal of Media and Culture 7 (4). Accessed October 10, 2016. http://journal.media-culture.org.au/0411/08-mole.php

Mulvey, Laura. 1989. Visual Pleasure and Narrative Cinema. In Visual and Other Pleasures, edited by Laura Mulvey, 14-26. London: Palgrave Macmillan.

Mumford, Laura Stempel. 1995. Love and Ideology in the Afternoon: Soap Opera, Women and Television Genre. Bloomington: Indiana University Press, 1995.

Nichols, Bill. 1994. Blurred Boundaries: Questions of Meaning in Contemporary Culture. Bloomington: Indiana University Press.

Schudson, Michael. 2013 [1984]. Advertising, the Uneasy Persuasion: Its Dubious Impact on American Society. London: Routledge.

Simon, Ron. 2005. The Changing Definition of Reality Television. In Thinking Outside the Box: A Contemporary Television Genre Reader, edited by Gary R. Edgerton and Brian Geoffrey Rose. Lexington: University of Kentucky Press.

Smythe, Dallas W. 1977. Communications: Blindspot of Western Marxism. Canadian Journal of Political and Social Theory 1 (3): 1-27.

Smythe, Dallas W. 2001. On the Audience Commodity and its Work. In Media and Cultural Studies: Keyworks, edited by Meenakshi Gig Durham and Douglas Kellner, 230-256. Malden, MA: Blackwell Publishing.

Spigel, Lynn. 1992. Make Room for TV: Television and the Family Ideal in Postwar America. Chicago: University of Chicago Press.

Turner, Graeme. 2010. Ordinary People and the Media: The Demotic Turn. London: SAGE. Wood, Allen. 2004. Karl Marx. London: Routledge.

Žižek, Slavoj. 1999. The Superego and the Act. The European Graduate School Faculty. Accessed February 20, 2017. http://zizek.uk/the-superego-and-the-act/

Žižek, Slavoj. 2008. The Sublime Object of Ideology. London: Verso.

\section{About the Author}

\section{Noam Yuran}

Noam Yuran is a research fellow in the Minerva Humanities Center and Edmond J. Safra Center for Ethics at Tel Aviv University. 